
"Outubro de 1982 que ela cura?*

\footnotetext{
"* CNRH/IPEA - As opiniós e perspectivas dos autores näo refletem necessariamente as posiçoes do IPEA.
}

\section{A mão invisível nos serviços de saúde: será}

\author{
Cláudio de Moura Castro ** \\ Nilton Romeu \\ Solon Magalhães Vianna
}

\section{A MÃO INVISÍVEL NOS SERVIÇOS DE SAÜDE: SERÁ QUE ELA CURA?}

Sejam quais forem as suas formas de prestação, os serviços de saúde têm de ser remumerados - simplesmente, as pessoas não trabalham de graça. Todavia, as configurações de mercado e os sistemas de preço interferem com a forma de prestação. Portanto, não podem ser ignorados ou tratados com ingenuidade.

$O$ presente ensaio discute, no contex to brasileiro, quatro casos de interação entre mercados e sistema de prestação de serviços de saúde.
a) Alguns administradores sempre insistiram para que Enfermeiros (nível universitário) tratassem os pacientes. Mas isso jamais aconteceu, devido à escassez relativa dessa mão-de-obra de escolaridade quase igual a dos médicos. Essa escassez relativa conduz a salários incompatíveis com a generalização desse tipo de atendimento.
b) A enorme expansão do número de médicos não gerou a grande redução no preço das consultas, ao nível dos consultórios particulares. Ao invés, foram criados inúmeros esquemas de seguros e empresas de prestação de serviços médicos que, em última análise, compram "por atacado" o trabalho dos médicos e o revendem por via de variados planos assistenciais.

c) A remuneração paga pela Previdência Social (salário ou honorário) parece corresponder a um preço de equilíbrio do mercado. Todavia, considerando-se sub-remunerados, os médicos ajustam seus rendimentos pelos expedientes de encurtar - unilateralmente - a jornada de trabalho, prolongar tratamentos ou adotar terapêuticas de custo mais alto.

d) Inúmeras escolas de medicina foram criadas nas maiores cidades brasileiras, na suposição de que a abundância de médicos nessas cidades levaria a sua migração para

Recebido para publicação em $28 / 08 / 85$ comunidades menores. Todavia, por muitas razões, isto não aconteceu. 
Sejam quais forem as suas formas de prestação, os serviços de saứde terão de ser pagos. De fato, médicos e enfermeiros, ou quaisquer outras categorias, não trabalham gratuitamente. As configurações de mercado e a estrutura de preço prevalescentes terão conseqüências sobre o sistema de prestações. Em outras palavras, existe um mercado, distribuindo renda, gerando incentivos e até mesmo distorcendo as intenções dos planejadores ou administradores. Por toda parte, está a mão invisível. Ela pode curar ou, parafraseando Joan Robinson, pode estrangular.

Portanto, o planejamento dos serviços de saúde requer, entre outras coisas, uma lúcida utilização da análise microeconômica. O mercado não é um deus ex machina, gerando resultados determinísticos e incontroláveis. Não obstante, não podemos ignorá-lo ou tratá-lo com ingenuidade. Este ensaio discute quatro exemplos de funcionamento de mercado no setor de saúde:

i) as forças do mercado podem prevalescer sohre as intenções dos administradores, gerando padrões de serviço e níveis de renda que fortemente discrepam dos planos iniciais. Por exemplo: enfermeiros treinados a nível universitário não tratam diretamente dos pacientes, como idealizado; ao invés disso, trabalham como administradores de enfermarias. Assim, os pacientes são tratados por pessoas de formação técnica mais singela. As condições de oferta e demanda são incompatíveis com a utilização de recursos humanos com níveis de escolarização tão elevado, para tarefas relativamente simples em sua gran de maioria.

ii) Rigidez, corporações de ofícios e cartelizacão podem restringir o livre jogo das forças de mercado. Como resultado, surgem outras formas de ajustamentos de preços, em decorrência das novas formas de organização dos serviços médicos. O crescimento extremamente rápido na oferta de médicos no Brasil deveria ter reduzido o preço médio da consulta médica. As associações médicas, contudo, estabelecem um valor mínimo para as consultas. A oferta crescente de mais e mais médicos pôde ser - em boa medida - acomodada, por via da criação de novas organizações que assalariam médicos, vendendo serviços em bases atuariais ou através de arranjos feitos diretamente com organizações voluntárias de empregadores. Os salários usualmente pagos a esses médicos, se traduzidos em preços de consulta, indicariam níveis significativamente mais baixos que o mínimo fixado pela Associação Médica. Em outras palavras, a tentativa de controlar os preços "no varejo" levou à criação de esquemas de compra "por atacado" em mercados menos controlados, 
transferindo-se parte das diferenças de preços para os consumidores, parte em forma de lucro, para as empresas empregadoras de mão-de-obra médica.

iii) Os salários pagos aos médicos dos quadros da Previdência Social são considerados por esses profissionais como excessivamente baixos, em comparação com suas aspirações.. Para compensar, os médicos reajustaram suas taxas de remuneração horária, pelo expediente de trabalhar menos tempo do que prescrito legalmente. As suas cotas mínimas de consultas são mantidas, mas a duração de cada consulta é reduzida. Nos casos em que o pagamento seja uma taxa fixa por consulta, como acontece com os profissionais "credenciados", alguma compensação pode ser obtida, seja adiando parte dos procedimentos para consultas subseqüentes, seja incorporando à consulta outros procedimentos melhor remunerados.

iv) Tentativas ingênuas de predizer os comportamentos do mercado podem fracassar. Irracionalidade? Diferentes funções de bem-estar? Ou, talvez, apenas predições canhestras ou inadequadas? As escolas médicas estão tradicionalmente localizadas nas cidades maiores. A crescente concentração dessas faculdades foi tolerada, por acharem alguns que a ocorrência de desequilibrios regionais na distribuição de médicos criaria diferenciais de renda capazes de estimular sua migração para áreas menos populosas. Mas, na verdade, isto não aconteceu no Brasil. Talvez a atração das grandes cidades justifique a renda perdida por não migrar para áreas onde haja maior escassez de médicos. Talvez os diferenciais de renda não sejam significativos, devido à maior riqueza dos grandes centros e por uma expansão da demanda de médicos induzida pela oferta. Ou mesmo, talvez, a dicotomização da medicina em dezenas de especialidades e subespecialidades obstacularizaria o exercício profissional em áreas desprovidas de diversificado aparato para complementação diagnóstica e terapêutica.

\section{A LÓGICA DO MERCADO E A LÓGICA DOS PLANEJADORES: QUEM DECIDE O PAPEL DO ENFERMEIRO?}

Esta seção explora um caso em que os educadores criaram soluções que contrariam a lógica de mercado. A escassez relativa de enfermeiros revelou-se mais importante do que os requisitos técnicos, na determinação de como funciona a enfermagem no Brasil.

Os médicos brasileiros educam-se em um curso póssecundário de seis anos. Isto segue de perto a tradição européia, na qual a educação médica é oferecida a nível de graduação. Por outro lado, a enfermagem, que é uma profissão de desenvolvimento mais recente, teve o seu perfil educati- 
vo formado no momento em que a influência norte-americana na educação brasileira era muito maior, isto é, no período de pós-guerra. A decisão de treinar enfermeiros por quatro anos, a nivel universitário, deve ter sido influenciada pela tradição americana de adiar o conteúdo vocacional ou profissional da escola. De fato, naquele país, oferecemse a nível superior muitas profissões que em outras partes são oferecidas no secundário. É de se notar que, mais do que mera idiossincrasia, este padrão simplesmente reflete a abundância relativa de pessoal de nível superior.

Em conseqüência, os médicos e as enfermairas brasileiras são preparados ao nível de escolarização. Os médicos apenas levam um pouco mais de tempo para terminar seu curso. Daí serem ambos recrutados do subconjunto de pessoas que terminam o segundo grau e são capazes de serem aprovados no exame vestibular. Para o país como um todo, isto significa um número relativamente pequeno de pessoas. Considere-se que, hoie em dia, dos cem que chegam à escola, dez terminarão o secundário e seis entrarão num programa de nível superior. Recrutar de um subconjunto tão pequeno da população significa restringir-se a um conjunto de pessoas com qualificações prévias atingidas por uma fração diminuta da população. Por isso, são elevadas suas expectativas de rendas.

Em termos dos custos de escolarização, a diferença é insignificante. De fato, muitas escolas de enfermagem, sendo pequenas e subutilizadas, podem ter custos por aluno/ano maiores do que certas escolas médicas.

Quando planejadores de saúde prescrevem a utilização de pessoal médico, eles apenas repetem os papéis convencionais de médicos e enfermeiros. Enfermeiros, mesmo treinados a nível universitário, supõe-se que devam cuidar de pacientes. De resto, o currículo de enfermagem reflete essa percepção de requisitos técnicos para a prestação de tais servicos. Esse é o exercício usual realizado pelas pessoas que fazem análise ocupacional e planejamento educacional.

Também trivial é a observação ex post facto de que tais exercícios valem de muito pouco, quando contrariam as condições de oferta e procura. De fato, os requisitos educacionais - não apenas para as profissões de saúde - dependem mais da oferta corrente de escolarização do que de exigências técnicas.

Convencionalmente se repete no Brasil que "para cada médico, cinco enfermeiros são necessários". Isto tem sido um dogma bastante repetido. Não é difícil demonstrar a vulnerabilidade de afirmativas tão descuidadas, se interpretadas literalmente.

Se há alguma proporcionalidade entre esforços educacionais e categorias profissionais, isto é, entre custo e bene- 
fício, deve-se esperar que níveis de formação similares gerem perfis de renda que não sejam excessivamente diferenciados. Vale dizer, esperar-se-ia que os salários de médicos e enfermeiros não diferissem demasiado, apesar da maioria dos serviços de enfermagem ser considerada mais simples do que muitos dos atos privativos dos médicos.

Claramente, os enfermeiros treinados a nível universitário não estariam dispostos a trabalhar por muito menos do que a classe média dos graduados de nível superior, em carreiras tidas como de menor prestígio, os quais, de toda maneira, recebem salários mais elevados do que graduados do segundo grau. Simplesmente, estas pessoas prefeririam outros trabalhos ou escolheriam outras profissões. E aqueles responsáveis pela administração e operação dos serviços de saúde não pagariam salários similares para as tarefas intrinsecamente mais simples que são as predominantemente realizadas pelos enfermeiros.

Examinando os números envolvidos, vemos também algumas constatações óbvias: o Brasil tem cerca de 100.000 médicos, daí, necessitaria de 500 mil enfermeiros. Numa situação de equilíbrio, cinco vezes mais enfermeiros do que estudantes médicos adicionariam 128 mil estudantes de enfermagem a uma matrícula universitária de 1,5 milhões. Mas, para alcançar a relação 1:5, digamos em dez anos, essa população esçolar deveria aumentar em 150 mil alunos, somando um total de 278 mil estudantes de enfermagem. Isto requereria expandir as escolas de enfermagem por um fator de 17. Esses cenários são claramente inviáveis. Ademais, não há vontade política para suportar o custo de tal tour de force.

No entanto, quando examinamos a situação vigente, encontramos que o mercado redefiniu a descrição ocupacional e o perfil da função do enfermeiro. $O$ mercado para pessoal de enfermagem treinado a nível universitário é de fato estável, exceto que os integrantes dessa categoria não trabalham como enfermeiros, mas como administradores de enfermarias. Em essência, eles supervisionam os serviços de enfermagem realizados por outras pessoas e recebem salários compatíveis com a responsabilidade e complexidade de tais funções administrativas.

O contato com o paciente é realizado na maioria dos hospitais brasileiros por atendentes e outros auxiliares, muitas vezes com treinamento precário apenas no local de trabalho. A essas funções correspondem salários muito modestos, significativamente menores do que os dos médicos e dos enfermeiros.

Quando examinamos os números, por exemplo, no Estado do Rio de Janeiro (que exibe a taxa recorde de um médico por 250 habitantes), encontramos 18 mil médicos, 
44 mil enfermeiros (nível universitário) e 27 mil "outros”. Evidentemente, os serviços de enfermagem são realizados pela categoria "outros". Somando a esse grupo de "outros" os enfermeiros universitários e comparando com o número de médicos, encontramos uma relação de 7:1 De fato, a OPS* sugeria uma relação de $2,4: 1$ como objetivo a ser alcançado na América Latina até 1980 . Tais cifras fazem muito mais sentido do que a relação de 5 para 1 idealizada pela tradição local.

Entretanto, muitos planejadores de saúde insistem em responder às demandas por enfermagem com exigências escolares excessivas, quando o mercado para enfermeiros de nível superior é estável, com um enfermeiro para cada cinco médicos. Isto, provavelmente, corresponderia à demanda por administradores de enfermaria, enfermagem de unidades de terapia intensiva e outras especialidades sofisticadas.

Do ponto de vista do sistema de saúde, essa solução envolve dois erros. Em primeiro lugar, devota-se atenção insuficiente à preparação das pessoas que vão ser "reais" enfermeiros. A custos muito modestos, um nivel de competência consideravelmente maior poderia ser obtido para o enorme exército de pessoal de nível elementar e secundário, que está, de fato, ocupado com os pacientes. No presente, o seu treinamento é deplorável. Empregadas domésticas, apenas alfabetizadas, são freqüentemente colocadas em posição de considerável responsabilidade, sem qualquer treinamento; o que talvez explique parte da prevalência de doenças iatrogênicas, como a infecção hospitalar.

Em segundo lugar, os médicos terminam realizando tarefas simples, tais como anotações, registros, tomadas de peso e temperatura, por exemplo, que poderiam ser delegadas a outras pessoas*, liberando tempo para uma anamnese mais cuidadosa ou para o atendimento de mais pacientes. Isto resulta do fato de que há um hiato de competência excessivamente grande entre os médicos e os auxiliares, já que muito pouca atenção foi devotada à preparação do pessoal de nível médio e elementar.

A lição é claríssima: as forças do mercado podem prevalescer sobre as intenções ingênuas dos planejadores. E, em última análise, os resultados não são necessariamente os melhores que se poderiam obter, dado o nivel de recursos.

\section{O QUE ACONTECE QUANDO HÁ MÉDICOS DEMAIS E NÃO SE PERMITE QUE CAIA O PREÇO DA CONSULTA?}

Cerca de duas décadas atrás, havia uma taxa de $2,5 \mathrm{mil}$ habitantes para cada médico no Brasil. Pensava-se que mais médicos significariam mais cuidados de saúde e, supostamente, a competição entre eles reduziria as quase-rendas derivadas do seu poder de monopólio sobre serviços de saúde.
* ORGANIZACION

PANEMAERICANA DE LA

SALUD - Plan Decenal de Salud para las Américas; informe final. Washington, OMS, 1973

(Documento Oficial, 118)

"Reunión Especial de Ministros de Salud de las Américas, Santiago, 1972".

* Tal desperdicio de tempo é funcional, no sentido de que mantém a demanda para médicos a niveis elevados. 
* Conselho Federal de Medicina. Código de Ética Médica. Diório Oficial da República, Janeiro/1965.
A expansão no ensino médico, a partir do final da década de 60 , foi impressionante. 0 número de graduados passou de 1,5 mil, em 1960, para mais de $8 \mathrm{mil} \mathrm{em} \mathrm{1980,} \mathrm{e} \mathrm{a}$ relação entre habitante/médico caiu para 1.200:1. No Estado do Rio de Janeiro, o número de graduados subiu de 350 para 1.360, entre 1960 e 1980.

Esses números são significativos e espelham um enorme esforço financeiro. Com uma oferta mais abundante de médicos, esperar-se-ia que o preço "de balcão" dos serviços médicos caísse consideravelmente. Entretanto, isto não aconteceu - exceto em circunstâncias muito restritas. Na verdade, as entidades médicas têm sido muito ativas na cartelização da prática privada, impedindo de fato que o preço das consultas caia. Tomando o Rio de Janeiro como um exemplo extremo de um local onde esta queda deveria ter acontecido, podemos observar que as consultas continuam caras. O preço mínimo estabelecido pela Associação Médica (1982) é da ordem de US\$ 16.00 por consulta.

Por outro lado, um dos fatores mais importantes para impedir a redução dos preços das consultas tem a ver com 0 Código de Ética Médica que explicitamente condena a concorrência ${ }^{*}$. Mais ainda, a noção equivocada, bastante difundida entre os consumidores, de que a qualidade da atenção médica é medida pelo preço da consulta pode também im. pedir a sua redução. Consultas mais baratas talvez não atraiam um número adicional de pacientes suficiente para gerar receitas mais elevadas.

Causa perplexidade o fato de que o preço dessas consultas não se reduza. Pressão dos pares, manipulação corporativa e ignorância do consumidor, provavelmente contribuem para essa inelasticidade de preços. Mas, permanece o fato de tratar-se de um mercado de livre entrada a todos os que têm diploma de médico.

Evidência prima facie sugere que tal rigidez de preços pode ter contribuído para a estagnação e mesmo a redução da prática privada em medicina. No início da década de 80 , na cidade do Rio de Janeiro, apenas $2,4 \%$ dos médicos na prática privada tinham menos do que trinta anos, enquanto que $33 \%$ tinham pelo menos cinqüenta anos.

$\mathrm{O}$ que acontece com esse número crescente de jovens médicos que encontram preços de consulta inelásticos $\mathrm{e}$ uma quantidade de demanda por consultas que cresce a uma taxa muito menor do que o seu número? Vendem seus serviços em outros mercados não regulados. A Previdência vem se expandindo muito rapidamente, absorvendo, hoje, nos seus próprios hospitais e centros médicos, 25.400 médicos, sendo 8.700 no Rio de Janeiro. Mas isto é apenas parte da estória. Os contratos de trabalho-padrão na previdência social - 20 horas por semana - deixam muito tempo livre e 
um "déficit" significativo no orçamento pessoal dos médicos, já que os salários mensais para tais contratos atingem, em média, perto de US\$ 450.00 .

Por outro lado, somente os pobres estariam dispostos a aceitar os desconfortos da Previdência (filas etc), para receber serviços de qualidade medíocre (consultas sumárias, atendimento impessoal, etc).

Assim, sobra muito tempo para os médicos, enquanto falta muita atenção de saúde com um certo nível de qualidade. Contudo, não aos preços regulados. Note-se que os serviços são regulados ao "varejo", deixando o mercado de "atacado" livre de restrições. Daí observar-se uma tendência clara à criação de esquemas que permitam aos "fregueses de varejo" comprarem a preços de "atacado".

Em última análise, tais esquemas envolvem a contratação de profissionais em base mensal, ao invés de por consulta. Essas soluções requerem organizações intermediárias para contratar os médicos e distribuir os seus serviços.

Diversos esquemas têm sido observados. As firmas podem contratar médicos e oferecer os seus serviços grátis ou a taxas nominais aos seus empregados. Empresas de serviços médicos contratam com grandes firmas para servir aos seus empregados. Planos atuariais, patrocinados por empresas de serviços médicos, permitem aos participantes serviços segundo suas necessidades e pagar suas contas médicas a "preços de desconto".

Esquemas como esses, e as numerosas permutações que permitem, parecem estar crescendo muito rapidamente* . Parecem atender a uma classe-média em expansão que não pode pagar os preços da prática privada e aspira ao conforto e atenção personalizada incomuns, para dizer o mínimo, nos ambulatórios previdenciários.

Talvez valha a pena descrever algumas das variedades mais comuns. Grandes firmas estão dispostas, por diferentes motivos, a oferecer aos seus empregados fringe benefits na área de saúde. $O$ esquema mais simples é contratar médicos e oferecer consultas gratuitamente aos seus empregados. $\mathrm{O}$ que interessa para nosso argumento é que o custo da consulta para a firma é muito menos do que o empregado pagaria se utilizasse a prática privada. Em outras palavras, os fringe benefits valem mais para o empregado do que a empresa paga por eles.

Alternativa cada vez mais freqüente são os "pacotes" entre firmas e médicos participantes. A firma - como comprador atacadista de serviços médicos - oferece um preço de "desconto" para seus empregados. Dependendo do preço oferecido, eles poderão atrair um segmento diferente do mercado. Com 10 a $30 \%$, ou até mais abaixo dos preços correntes, até alguns dos melhores médicos estariam dispostos
"A "medicina de grupo" emprega hoje trinta mil pessoas, incluindo doze mil médicos, e cobre mais de 10 milhóes de pessoas. 
* De fato, aumenta a pressāo, atualmente, para congelar ou mesmo reduzir a matrlcula nas escolas médicas. "Saturação" do mercado e a qualidade deficiente da educação médica são as justificativas explicitas. a participar. Para eles, significa atrair um número significante de clientes novos, de acordo com a velha lógica do desconto para quantidade. Alternativamente, a firma pode fixar preços muito mais baixos, tentando atrair profissionais mais jovens que não têm uma clientela extensa. Nesses casos, uma clínica ou um hospital poderia servir de intermediário para o empregador contratante.

Os custos para tais esquemas são compartilhados pela empresa e pelos empregados. Usualmente, os empregados concordam em pagar o custo de uma certa proporção (digamos 50\%) do preço de "desconto" mais baixo de todos. Aqueles empregados que preferem as alternativas mais caras pagariam uma fração maior do preço da consulta.

Novamente o subsídio (ou os fringe benefits) não é o que interessa. A questão é a redução no pagamento que percebem os médicos. Uma variante do esquema acima são as empresas médicas que atendem às grandes firmas empregadoras. Esse talvez seja o exemplo mais transparente do que estamos tentando descrever nesta seção. Essas organizações de saúde contratam médicos a um salário mensal e vendem consultas às empresas a preços de "desconto". Comumente alcançam uma considerável margem de lucros, mas, ainda assim, conseguem oferecer serviços que estão a um preço muito mais baixo do que o "varejo".

Os planos médicos em bases atuariais também começam a crescer. Algumas organizações vendem seguros de saúde com um prêmio mensal. Parece razoável acreditar que o valor real do serviço esteja abaixo dos preços de mercado.

Que aprendemos no exame desses casos? Inicialmente, a cartelização tem um êxito apenas parcial ${ }^{*}$. Se o preço das consultas privadas não pode cair, alguns participantes encontrarão outras modalidades para contratar serviços médicos. Esses tendem a convergir a preços de equilıbrio mais baixos, permitindo que um volume maior de serviços seja transacionado.

Para os médicos e para os clientes, essa é uma solução do tipo "mal-menor". Tais esquemas permitem o equilíbrio do mercado, contornando a rigidez dos preços de varejo. Entretanto, introduz-se uma classe de intermediários do mercado, que obtém lucros e cobra taxas por seus serviços. Esse excedente do consumidor poderia ter sido apropriado pelos clientes e pelos médicos. Mais ainda, burocratiza os serviços médicos dos hospitais, das organizações médicas e das empresas participantes. Papelório e os salários dos burocratas são incorporados ao sistema, sem que se materializem as vantagens de formatos mais integrados de atendimento médico.

Quem se beneficia? Principalmente os médicos mais experientes, com prática privada consolidada e que podem se 
proteger da competição de preço das novas levas de doutores que entram no mercado. Com consultas mais baratas, alguns clientes aceitariam profissionais menos experimentados, mas, se os preços são os mesmos, por que se satisfazer com menos do que experiência e notoriedade?

\section{O QUE ACONTECE QUANDO O MAIOR EMPREGADOR DE MÉDICOS PAGA POUCO?}

A Previdência Social brasileira (INAMPS) assalaria $25 \%$ dos 100.000 médicos brasileiros. Outros $16 \%$ são contratados por prestação de serviços (credenciamento). Trata-se, naturalmente, do maior empregador do sistema de saúde. Dada a grande expansão das escolas médicas e a cartelização da prática médica, a Previdência é oligopsonística, operando num mercado de compradores. Portanto, estabelece preços que são muito baixos, comparados com os preços tradicionais e convencionais da prática privada, ou mesmo com aqueles das organizações médicas voltadas para a classe média. Contudo, dada a estrutura de mercado que prevalece, eles não encontram problemas de encontrar candidatos para as suas posições. De fato, o número de candidatos para o concurso de 1976 atingiu $77 \%$ de todos os médicos brasileiros.

Não obstante, os médicos estão insatisfeitos com a sua remuneração. Entendem que o seu nivel de salário conflita com sua noção de um "preço justo" para os seus serviços.

Tais percepçōes subjetivas talvez não tivessem maiores conseqüências, se a administração das unidades de saúde não fosse exercida por médicos, os quais se identificam com seus colegas eventualmente subordinados. A única solução para aumentar a taxa de remuneração é reduzir o total de horas trabalhadas. De acordo com as regras estabelecidas, os médicos têm uma cota mínima de pacientes para ser atendida. Uma prática bastante comum é atender a esses pacientes em menos tempo do que o contratual e sair mais cedo. Não seria possivel neste ensaio tentar quantificar a freqüência de tais reduções de carga de trabalho.

A Previdência compra também serviços de hospitais e clínicas. O formato usual é pagar aos produtores uma taxa-padrão por consulta. Esta taxa situa-se em $13 \%$ do valor mínimo defendido pela Associação Médica para consulta privada. Novamente, esta taxa é percebida como excessivamente baixa pelos médicos, ainda que as condições de oferta e demanda indiquem que não está abaixo do preço de equilibrio. A maneira de contomar esta remuneração é procrastinar, multiplicando o número de consultas ou adicionando outros procedimentos melhor remunerados. Por exemplo, exames de laboratórios são pedidos para que se adie o diag-

Caderno de Saúde Pública, R.J., 1(4) : 418-431, out/dez, 1985. 
* Cerca de $30 \%$ de todos os médicas brasileiros trabalham na cidede do Rio de Janeiro. nóstico. Procedimentos que poderiam ser realizados numa única consulta são transferidos para a próxima ou rotulados como de emergência para, às vezes, apenas justificar cobranças adicionais. Em resumo, esta seção descreveu uma situação onde as instituições que contratam médicos redefinem os preços de equilibrio diferentemente das tendências de mercado e eventualmente contra os seus próprios interesses. A explicą̧ão parece residir nas noções acerca do que seja o "preço justo" para consultas por parte dos administradores de saúde que sejam médicos de formação.

\section{POR QUE OS MÉDICOS NÃO EMIGRAM DE UM MERCADO SATURADO?}

Os livros-texto de Economia afirmam que os produtores maximizam seus lucros. Desequilibrios de mercados entre regiøes deveriam gerar fluxos migratórios, sendo abandona. dos os locais onde o excesso de produtores reduza os preços. No caso oposto, nos locais onde a oferta é mais escassa, os preços sobem, atraindo produtores de fora.

Como já mencionado, o Rio de Janeiro é um bom exemplo de um centro cultural e economicamente desenvolvido. Além de ter um grande número de escolas médicas, atrai médicos de outros estados* . O resultado de tal polarização em torno do Rio é uma relação de médicos por habitante muito acima da média nacional.

Esse desequilíbrio na oferta de médicos no Rio de Janeiro seria au to-corrigivel; pelo menos assim se esperaria. $0 \mathrm{ex}$ cesso na oferta de médicos puxaria para baixo a sua renda, tornando outras localidades mais atraentes, sobretudo para os recém-graduados.

Entretanto isso não vem acontecendo. Apesar dos sinais claros de um mercado deprimido, a emigração não ocorre em números consideráveis. De acordo com um relatório da Associação Médica, publicado em 1979, apenas $12 \%$ dos médicos deixam o Rio após haverem trabalhado lá.

Onde está o erro? Por que não houve emigração? Será que a teoria de mercado fracassa na descrição de seu comportamento? Teria o comportamento dos médicos pouca racionalidade?

Antes de prosseguir, cabe discutir algumas questões de método. Qual o significado das expressões: "comportamen. to irracional" e "a teoria do mercado não funciona"?

Os economistas têm uma noção muito estreita do que seja racionalidade ou a sua ausência. Diz-se que o comportamento é irracional se este é inconsistente ou intransitivo. Em outras palavras, se A é preferido a B, B não pode ser preferido a $A$ na próxima vez. Além disso, se $A$ é preferido a B, B é preferido a C, então A deve ser preferido a C. 
Gostar mais de amarelo do que de verde, gostar mais de lazer do que de dinheiro, preferir engarrafamentos a mosquitos são preferências cuja legitimidade não pode ser discutida e que está implícita na "preferência revelada" dos individuos. Nenhum economista competente diria que o comportamento é determinado por razões puramente pecu. niárias. Daí "comportamento irracional" é um termo que descreve um comportamento estranho.

A teoria de preços está errada? Provavelmente não. Pode ser tautológica, o que é ainda pior, mas não errada; a não ser que estivéssemos igualando teoria dos preços à teoria da concorrência perfeita.

O problema com a introdução de imperfeições e complexidades nos mercados é que a teoria perde o seu poder preditivo. Já que a importância relativa dos múltiplos fatores não pode ser quantificada, ou mesmo avaliada, o resultado é imprevisível. Neste sentido, torna-se algo tautológica. $O$ comportamento observado é o que permite a identificação e a escolha desta ou daquela explicação.

Seja como for, é um exercício instrutivo refletir sobre o caso do excesso de médicos no Rio de Janeiro, já que este é um bom exemplo de sua concentração em grandes áreas metropolitanas do país. De fato, há realmente um desequilíbrio na densidade de médicos, quando comparado com cidades menores. Por outro lado, observa-se que a emigração não é mais alta do que imigração. Portanto, poderíamos dizer que, ou os atrativos econômicos para a emigração são fracos, ou esses são obliterados por considerações nãoeconômicas.

Várias explicações são cabíveis:

i) a redução de renda como resultado da concorrência não é suficiente para criar uma vantagem líquida para emigração. Grandes centros como o Rio podem ter uma renda per capita tão mais alta que outras áreas, que os médicos permaneceriam em situação melhor, apesar do crescimento de seu número. Foi observado que a oferta de serviços médicos cria a sua própria demanda* . Este pode ser o caso no Rio: não haveria um excesso; apenas mais médicos e mais demanda por eles. Infelizmente, dados completos de renda pessoal não estão facilmente disponiveis para verificar esta hipótese ${ }^{* *}$.

ii) a decisão de emigrar é praticamente irreversível. Levase muitos anos para desenvolver uma reputação e um círculo de clientes. Nenhum deles pode ser trazido mais adiante para o Rio. Os médicos consideram as cidades pequenas como indesejáveis do ponto-de-vista de sua carreira. A logística, os serviços auxiliares e o fluxo de informações são inadequados, considerando-se que as escolas de medicina estimulam perfis de carreira altamente especializados. Em outras
"Karen Davis "Implications of an Expanding Supply of Physicians: Evidence from a cross-sectorial analysis". The Johns Hopkins Medical Journal 150 n? 2 (February 1982).

** Tabulaçōes nāo-publicadas dos dados das declaraçóes do Imposto de Renda sugerem que os salarios médicos (ñ̃o a renda) são mais baixos que na maioria dos outros Estados. Infelizmente, a interpretação não é clara, dadas posstveis diferenças na freqüência com que os médicos têm múltiplos empregos (a média nacional está próxima de dois). 
palavras, os médicos tomam uma perspectiva de longo prazo para suas carreiras e percebem os grandes centros como uma escolha melhor, apesar das dificuldades iniciais.

iii) uma outra explicação tem a ver com o risco e falta de informação. Podem ser fatores suficientes para impedir a emigração. Mudar-se para um local desconhecido, onde há falta de informação acerca do potencial do mercado, além do medo de excessivas responsabilidades em locais onde há pouca assistência médica especializada.

iv) razões freqüentemente mencionadas são as amenida. des e o pluralismo das opções de lazer disponíveis nos grandes centros. Os estilos de vida e os padrões culturais das cidades maiores não compensariam os diferenciais de renda existentes. Em outras palavras, os médicos estariam dispostos a abrir mão de alguns benefícios econômicos, a fim de preservar certos hábitos e estilos de vida.

Seja qual for a explicação, os médicos preferem ficar nos locais onde as estatísticas de densidade sugerem um excesso de oferta. Eles têm suas razões, sejam econômicas ou de outros tipos. A lição que se pode derivar desse exemplo é que não se pode esperar que desequilíbrios na densidade de médicos gerem uma migração compensa tória. Não fica claro se as taxas de salário não refletem essas discrepâncias quantitativas, ou se os incentivos econômicos não são suficientes para superar as vantagens locacionais dos grandes centros. Mas uma conclusão é clara: não se pode especializar grandes áreas urbanas como produtoras e exportadoras de médicos. Os médicos devem ser treinados não muito longe de onde se espera que eles trabalhem, se é que deve permanecer a sua liberdade de escolha de local de trabalho.

\section{LIÇÕES}

Neste ensaio, discutimos quatro exemplos de estrutura de mercado no setor saúde. No caso dos enfermeiros, as forças de mercado foram ignoradas pelos educadores. Não obstante, tais forças são poderosas e levaram a resultados totalmente diferentes do que se esperava. De fato, os enfermeiros encontraram outro mercado: a administração de serviços e o treinamento de auxiliares.

$\mathrm{O}$ oposto aconteceu com os desequilíbrios geográficos na oferta de médicos. Supunha-se que os incentivos de mercado levassem à migração. Não obstante, esta nunca se materializou. Os médicos permaneceram nos grandes centros, onde se graduaram. Por alguma razão, os incentivos não foram suficientes. A rigidez de preços, de alguma forma, impediu que o aumento na oferta de médicos levasse a uma queda no preço das consultas. Ao invés, outras formas menos dispendiosas de prestação de serviços médicos foram desenvol- 
vidas. A prática privada permanece protegida, enquanto o aumento na oferta de médicos pressiona a medicina institucionalizada.

Os salários dos médicos empregados na Previdência são considerados excessivamente baixos, em contraste com as suas expectativas. Estranhamente, essas preconcepções sobre "preço justo" parecem ter um papel importante, já que os administradores de serviços de saúde são médicos que também compartilham de tais noções.

Para resumir, o setor saúde apresenta estruturas de mercado complexas e nada óbvias. São difíceis de compreender e algumas vezes vão ao arrepio de predições pouco sofistica. das. Contudo, elas influenciam criticamente os padroes de atendimento médico. Portanto, não podem ser ignoradas.

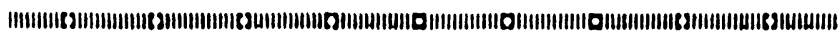

\section{THE INVISIBLE HAND IN HEALTH: DOES IT HEAL?}

Health services have to be paid for, regardless of the prevailing economic system. Pricing systems and market structures interfere with the deployment of health services, therefore have to be dealt wity realistically.

This essay discusses four cases of interactions between markets and health delivery systems in Brazil.

a) Generally, health administrators indicated that university-trained nurses should treat patients. This has never happened due to the relative scarcityand consequent high wages - of nurses trained, at levels almost equivalent to that of doctors.

b) Since price of consultations is taken as a measure of quality, the enormous expansion in the number of medical doctors did not lead to lower prices that could clear the market. Instead, a very large number of insurance and medical sevice firms were created to purchase doctors' time at "wholesale" and resell it under a variety of health plans.

c) Social Security services pay physicians salaries and fees which are competitive in the market but are considered too low by the doctors. As a consequence, doctors decrease, on their own initiative, the number of hours worked or procrastinate treatment in order to require more consultations.

d) Several medical schools were created in the large Brazilian cities, under the assumption that the oversupply of doctors would generate an outflow of graduates towards smaller communities. For several reasons this never materialized. 